\title{
L'Italia dei Divieti: entre o sonho de ser européia e o babado da prostituição*
}

\author{
Flávia do Bonsucesso Teixeira**
}

\begin{abstract}
Resumo
O sonho do deslocamento entre Brasil-Europa pode ser encontrado de forma recorrente na bibliografia sobre a temática travesti. As modificações relativas ao tráfico de pessoas realizadas no Código Penal brasileiro, em 2005, possibilitam diversas interpretações para os termos facilitar e facilitação, criminalizando ações que, para este grupo, se constituíam, até então, como formas de sociabilidades. Argumento que o não reconhecimento da prostituição como um trabalho distancia essas travestis de outras brasileiras que trabalham indocumentadas, potencializando o envolvimento destas em situações de vulnerabilidade.
\end{abstract}

Palavras-chave: Travestis, Migração, Prostituição, Tráfico de Pessoas.

\footnotetext{
* Recebido para publicação em agosto de 2008, aceito em setembro de 2008. Este artigo foi originalmente apresentado no Seminário Gênero no Tráfico de Pessoas promovido pelo Núcleo de Estudos de Gênero - Pagu/Unicamp e o Projeto de Combate ao Tráfico de Pessoas do Escritório da Organização Internacional do Trabalho no Brasil. Agradeço a Adriana Piscitelli pela orientação, a cuidadosa leitura $e$ as contribuições ao texto final, a Adriana Vianna pelo generoso incentivo durante o debate e a Karla Bessa pela inspiração e críticas durante o trabalho de campo.

** Doutoranda em Ciências Sociais - área de Estudos de Gênero - Unicamp; Docente da Universidade Federal de Uberlândia. fb-teixeira@uol.com.br
} 
Ser européia e o babado da prostituição

L'Italia dei Divieti:

In Between the Dream of Being European and the "babado" of

Prostituition

\begin{abstract}
The dream of traveling between Brazil and Europe is easy to find in the referential bibliography about transvestites. The changes related to the trafficking in persons, in the Brazilian penal code in 2005, show how different interpretations of the terminology "facilitate" and "facilitation" made a strong impact on transvestites' lives, criminalizing some practices of this group that had in fact been part of their sociability. I argue that the unrecognized position of prostitution as legal work creates a substantial gap between the transvestites and the other illegal Brazilian workers, which leads them into potentially vulnerable situations.
\end{abstract}

Key Words: Transvestites, Migration, Prostitution, Trafficking in Persons. 
Flávia Teixeira

\section{Introdução}

Neste texto trato da circulação das travestis brasileiras entre Milão, Roma e Brasil. Utilizo aqui o termo êmico européia ${ }^{1}$ para argumentar que os sonhos e as experiências de circulação entre as fronteiras Brasil-Europa integram o universo das travestis com sentidos que podem se afastar daqueles atribuídos pelos órgãos oficiais e outras organizações envolvidas no combate ao tráfico de seres humanos.

Os cenários da prostituição surgem como significativos espaços de sociabilidades no campo de diferentes pesquisadores que se aventuraram a investigar o cotidiano das travestis desde o trabalho inaugural de Helio Silva (1993). ${ }^{2}$ Também não escapou a eles o fascínio que a Europa exercia e ainda exerce neste universo. O fluxo migratório das travestis foi identificado por Don Kulick (1998, 2008) desde os anos 70 tendo a França como destino preferencial até 1982. Segundo Larissa Pelúcio (2005), esse fluxo se acentuou nos anos de 1980 e nos anos 90 a Itália se consagrou como o destino preferencial das travestis. Embora, a partir do início deste século, países como a Espanha, a Suíça e a Holanda passaram a integrar o roteiro das travestis, identifico a supremacia italiana captada no uso do idioma, nas escolhas das grifes de roupas e perfumes, nos hábitos alimentares das travestis. A experiência de ter vivido na Europa (ou mesmo conhecer alguém que tenha realizado a viagem) integra as conversas que circulam nas calçadas, salões de beleza, clínicas de cirurgia plástica e nas casas, alimentando o desejo de muitas outras que esperam um dia atravessar o Atlântico.

\footnotetext{
1 Segundo Larissa Pelúcio (2005), para ser considerada européia a travesti deve ter vivido uma temporada atuando como prostituta fora do Brasil. Assim como babado é também um termo êmico, mas que carrega a ambigüidade, pode tanto significar algo muito bom ou desastroso; só pode ser apreendido no contexto.

2 Neuza Oliveira, 1994; Don Kulick, 1996, 1998, 2008; Larissa Pelúcio, 2005, 2007; Mônica Siqueira, 2004; Marcos Benedetti, 2005; Wiliam Peres, 2005.
} 
Ser européia e o babado da prostituição

As reflexões aqui desenvolvidas estão ancoradas na pesquisa que coordenei sobre vulnerabilidades e prostituição das travestis em Uberlândia e que originou em 2006 o projeto de extensão: "Em Cima do Salto: saúde, educação e cidadania", vinculado à Faculdade de Medicina da Universidade Federal de Uberlândia, ainda em execução. Durante esse período, identifiquei a intensificação do uso de termos em italiano como ciao, bella, grazie, regina, cazzo, aiutami no vocabulário das travestis de Uberlândia. ${ }^{3}$ Não passaram despercebidas as músicas italianas que, juntamente com sucessos de época, embalaram muitas das festas nas quais compareci. A valorização do idioma italiano e sua fluência como capital simbólico pode ser flagrada nos seus álbuns de relacionamento do orkut. ${ }^{4}$ Argumento que a vivência da prostituição e o sonho de trabalhar na Europa integraram o universo da travesti, compondo sua subjetividade. A percepção das estratégias migratórias desenvolvidas com o propósito de materializar esse sonho são frequentemente dissonantes dos argumentos das agências oficiais do uso de engano ou fraude $e$ mesmo de aliciamento. ${ }^{5}$

Segundo Piscitelli (2004), a partir dos anos 90, o debate que associa prostituição forçada, o turismo sexual e a prostituição se tornou visível no Brasil, chamando a atenção da opinião pública, dos pesquisadores e dos formuladores de políticas. No entanto, a

\footnotetext{
${ }^{3}$ É um projeto que atende em média, 40 travestis por mês. As atividades são semanais e devido a rotatividade do grupo, estimamos que mais de 150 travestis integraram as atividades em algum momento.

4 Plataforma de sociabilidade virtual na qual os componentes do perfil do usuário ficam disponíveis para consulta.

${ }^{5}$ Ressalto que considero problemática a relação direta entre ser travesti e ser prostituta ou que a prostituição é naturalmente um único caminho para as travestis, mas compartilho com outros pesquisadores a percepção de que as calçadas são significativos espaços de sociabilidade. Remeto-me aqui ao reconhecimento de que a maioria das travestis, cerca de $97 \%$, vivencia a prostituição como trabalho, conforme dados obtidos durante I Consulta Nacional sobre DST/Aids, Direitos Humanos e Prostituição que ocorreu em Brasília entre 26 e 28 de fevereiro de 2008.
} 
inclusão das travestis nesses debates é recente ${ }^{6} e$ decorre principalmente das alterações introduzidas no Código Penal brasileiro em março de 2005, que substituiu a palavra "mulheres" por "pessoas". Essa modificação impactou a vida das travestis, porque a partir de uma lógica jurídica na qual sexo corresponde a gênero, as travestis anteriormente estavam incluídas no universo de homens e, portanto, fora do alcance jurídico da esfera desse tipo de tráfico. As alterações dos artigos 231 - que faz referência ao crime de tráfico internacional de pessoas para fins de exploração sexual - e a introdução do mesmo artigo, que caracteriza o tráfico interno - introduziram para as travestis, no plano técnico, um conjunto de questionamento sobre práticas que, até então, integravam seu universo regidas por uma lógica completamente distante e diversa das disposições do Código Penal. $^{7}$

Referendada nos fragmentos da pesquisa de campo, problematizo dois aspectos que impactam a vida das travestis: o primeiro, relacionado ao Código Penal Brasileiro, não contempla a possibilidade de que uma pessoa possa realizar a migração voluntária para trabalho sexual e/ou receber auxílio de outro e a realização desse desejo termina por criminalizar algumas estratégias de acionamento de redes sociais que são legitimamente acionadas em contextos fora da prostituição através de termos como help, ajuda (Assis, 2007; Piscitelli, 2008). O segundo, a

${ }^{6}$ No documento da pesquisa realizada pela Secretaria Nacional de Justiça do Ministério da Justiça e Organização Internacional do Trabalho (OIT), e divulgado em 2007, está explícito o reconhecimento de que a categoria "cafetina" é pouco problematizada nos debates sobre o tráfico, assim como no universo dos operadores do direito, desconsiderando a forma êmica que possui para as travestis, nem sempre remetendo à noção de exploração, mas de ajuda e afeto.

7 No meu campo de pesquisa, entendo que a Operação da Polícia Federal denominada "Caraxué" em 18 de outubro de 2006 e tendo entre os espaços de intervenção a cidade de Uberlândia, mesmo repercutindo na mídia como sendo uma ação exitosa de combate ao tráfico de seres humanos, entre as travestis significou uma verdadeira confusão, pois estas não atribuíam nexo entre as ações de seu cotidiano e o que estava sendo denominado como tráfico de pessoas. 
Ser européia e o babado da prostituição

paradoxal atuação de ONGs que atuam no combate ao tráfico $e$ na proteção das vítimas no exterior. $\mathrm{O}$ não reconhecimento por parte das travestis de que são/foram exploradas/traficadas cria uma situação ambivalente, ora o discurso oficial empregado pelas ONGs coloca as travestis no lugar daquelas consideradas traficadas, exploradas e, portanto, necessitam de proteção ou as deslocam para a situação de "perigosas e bandidas" ao vincular a prostituição à marginalidade (indocumentadas ${ }^{8}$ ) e à (des)ordem pública.

Não afirmo que as travestis que se prostituem na Itália ou em Uberlândia não possam ser traficadas ou exploradas, nos termos do Protocolo de Palermo, em processos que envolvam coação ou fraude, mas, como mostram outros estudos (Davida, 2005), é necessário diferenciar as problemáticas, considerando as lógicas dos sujeitos envolvidos.

\section{O campo}

Utilizo-me de algumas referências para argumentar que Uberlândia, apesar de situada no interior do Triângulo Mineiro, é um espaço representativo do universo das travestis. Esse destaque pode ser flagrado, por exemplo, quando a BEMFAM (2006) recortou Uberlândia (MG) como um dos espaços para a pesquisa sobre prostituição e HIV/Aids. Conforme observa o próprio documento, a população inicial do estudo seria apenas motoristas de caminhões e mulheres profissionais do sexo. A ampliação da pesquisa envolvendo também as travestis se deu em função do reconhecimento do número expressivo de travestis que trabalham na cidade como prostitutas e suas possíveis interações com os caminhoneiros.

Uberlândia também foi citada no documento da Organização Internacional do Trabalho (OIT, 2006) como rota para

8 Segundo Gláucia Assis (2007), "indocumentado" refere-se aos imigrantes que não possuem os documentos que os autorizariam a trabalhar em um país estrangeiro. 
o tráfico de seres humanos, a partir da Pesquisa sobre Tráfico de Mulheres, Crianças e Adolescentes para Fins de Exploração Sexual Comercial (Pestraf, 2002). Penso que a justificativa para essa inclusão, já que Minas Gerais não foi uma região pesquisada para o relatório da Pestraf (2002), pode estar associada aos relatórios da Polícia Federal envolvendo investigações sobre tráfico de mulheres. Certamente, Uberlândia seria incluída nos próximos relatórios após evento, amplamente divulgado na mídia nacional, da prisão realizada pela Polícia Federal, em 2006, de duas travestis acusadas de envolvimento no tráfico de seres humanos. ${ }^{9}$

Aprendi o bajubá ${ }^{10}$ no cotidiano das ruas como a maioria dos antropólogos que fizeram suas etnografias nas calçadas deste país. As reflexões aqui desenvolvidas estão ancoradas no trabalho de campo que consistiu em acompanhar o cotidiano das travestis nas calçadas, nas casas, nas festas de aniversário, Natal e Ano Novo, nas reuniões do projeto e nas situações de doradoecimento, morte e violências. Nesse período, acompanhei os preparativos de algumas travestis para trabalhar na sonhada Itália. A poupança destinada aos investimentos corporais que incluem a colocação das próteses de silicone nos seios, a depilação do rosto a laser, a colocação de apliques ou perucas, a obtenção dos documentos, a compra das passagens. Foram aqui tecidos os fios de um vínculo, permitindo que as entrevistadas falassem de assuntos considerados delicados, entre eles, os acordos que conduzem à Europa.

Além da observação e contatos estabelecidos com travestis em Uberlândia a partir de 2002, para este trabalho realizei seis entrevistas em profundidade, o critério inicial para escolha da

9 Remeto-me aos artigos de Adriana Piscitelli (2004) e Grupo Davida (2005) para pontuar a necessidade de problematizar a produção de fatos, pois acredito que tráfico não seria a categoria adequada para nomear esse evento em particular.

${ }^{10}$ Gíria amplamente utilizada pelas travestis composta por termos oriundos do ioruba-nagô, conhecida também como pajubá ou bate-bate. 
Ser européia e o babado da prostituição

entrevistada seria a experiência de ter vivido na Itália como prostituta. Outros critérios foram estabelecidos com o objetivo de apresentar a heterogeneidade do grupo, e escapar (ou tentar escapar) da simplificação desse fenômeno. Duas de minhas entrevistadas são proprietárias das chamadas casas de pensão para travestis, outras duas são travestis que migraram para Itália com financiamento próprio e retornaram após a primeira temporada, duas utilizaram o esquema de financiamento de outras travestis, entre elas, duas documentadas - uma residente na Itália e outra no Brasil.

A partir de março de 2008 tornou-se evidente a chegada, em Uberlândia, de um maior número de travestis vindas da Itália. Esse movimento motivou parte da pesquisa de campo realizada em Roma (Itália) em maio de 2008 com o objetivo compreender a extensão das políticas migratórias implementadas pelos governos de Silvio Berlusconi e Gianni Alemanno no cotidiano das travestis brasileiras residentes na Itália e explicitadas nas diferentes justificativas que elas apresentavam quando indagadas sobre o período que pretendiam permanecer por aqui. Foram recorrentes as expressões: "a Itália está o Ó"; "vim descansar, mas também esperar as coisas esfriarem por lá"; "parece a mesma perseguição que aconteceu na França, eles vão tombar a Itália”.

Em Roma, foram entrevistadas a presidente da Associação das Travestis, uma brasileira com nacionalidade italiana ${ }^{11}$, a coordenadora da Unidade de Estrada V da Cooperativa Social PARSEC - Projeto Roxanne $e^{12}$ - e uma das mediadoras culturais -

\footnotetext{
${ }^{11}$ Associação Libellula ArciTrans Roma. A questão do enfrentamento do tráfico de pessoas e da exploração sexual não consta entre os objetivos da Associação listados no Sítio e não apareceu como demanda para a instituição durante a entrevista. Disponível em http://www.libellula2001.it/ (consultado em 04/08/2008).

${ }^{12} \mathrm{O}$ projeto Roxanne prevê atividades de prevenção, ajuda e encaminhamento ao trabalho de pessoas vítimas do tráfico sexual. Funciona através das Unidades de Estrada e está vinculado ao Comune di Roma, conforme sua página oficial (http://www.spqrdipsociale.it/disagio_sociale/tratta_sessuale.asp).
} 
também brasileira - responsável pela distribuição de preservativos, pelo contato nas ruas dessa região adstrita e também uma das tradutoras no Tribunal Penal em Roma nas situações em que o juiz decide sobre a permanência ou deportação de alguma travesti.

\section{O masculino das travestis e os vazios nas pesquisas}

Nos documentos oficiais, em relação ao casamento, as preocupações são direcionadas para as mulheres brasileiras, um universo no qual as travestis sequer são citadas. $\mathrm{O}$ casamento com um italiano não desponta no horizonte das expectativas de minhas entrevistadas, nem como porta de entrada para a migração ou permanência com a obtenção de cidadania. No entanto, cabe o alerta de Adriana Piscitelli (2007b) de que a heterogeneidade e a complexidade das relações precisam ser pontuadas. É necessário considerar que as travestis, pelo menos no plano jurídico, estão incluídas na categoria sexo masculino $e$, na Itália, não se reconhece o casamento de pessoas do mesmo sexo. Nesse caso, ao pensarmos os casamentos mistos ocorridos na Itália, chamo a atenção para os casamentos que devem constar nos documentos oficiais como sendo de um homem brasileiro com uma mulher italiana e que pode ser o de uma travesti brasileira com uma mulher italiana. Não são raros os casos em que esse "arranjo matrimonial" ocorre.

Rita é viúvo, casou-se com uma italiana em 2004 após uma negociação de 8.000 Euros. Pergunto sobre suas amigas travestis que identifico através das fotografias que ela vai me mostrando, $e$ ela narra como cada uma das "documentadas" percorreu caminhos semelhantes.

Viviane é cidadã italiana, herdeira do nome do avô, neta de um migrante que chegou ao Brasil no final do século XIX. Primeiramente, ela ficou constrangida quando percebeu que eu havia compreendido que falava com suas amigas sobre um arranjo matrimonial. No entanto, era dia de festa e com um 
Ser européia e o babado da prostituição

sorriso sentou-se mais perto para falar de seus planos futuros. O sobrenome italiano poderá render-lhe muitos Euros caso concorde com a proposta de uma prostituta brasileira residente na Itália. Ela fala com receio do caso, acredita ser constrangedor que os outros saibam que se casou com uma mulher. No entanto, oficialmente, essa união seria registrada como o casamento de um italiano com uma brasileira. Apesar de ter cidadania e também ter residido na Itália, Viviane não pensa em retornar.

Priscila conta as diferentes histórias das travestis que conheceu vivendo na Itália nesses oito anos em que realiza o deslocamento Brasil-Itália-Brasil e fala sobre o anonimato das mortes das travestis:

nunca vi um cemitério com a placa de identificação de uma travesti que tenha morrido lá... permanecem todas sem nome, como indigente. Para dizer a verdade, conheço uma. Uma teve velório e enterro porque a mulher dela fez, mas enterra como homem.

As mortes das travestis, quando registradas, integrariam as estatísticas como pessoas do sexo masculino, ou seja, homens que faleceram no exterior. O mesmo ocorre nas pesquisas sobre tráfico de pessoas, as travestis deixam o país como pertencentes ao sexo masculino e nesta categoria também são informadas durante os retornos. Em análises qualitativas, essa particularidade pode ser assinalada, a exemplo da pesquisa sobre pessoas que foram deportadas ou não admitidas e que regressam ao Brasil via aeroporto de Guarulhos, na qual os pesquisadores tiveram o cuidado de separar homens, mulheres e transgêneros (Secretaria Nacional de Justiça, 2007).

\section{Os acordos de viagem}

O discurso oficial, compartilhado pela opinião pública, é que a ausência de denúncias por parte das travestis seria justificada pelo medo dos traficantes que compõem as redes e das 
situações de vigilância e violência a que estão submetidas. Novamente enfatizo que podem existir travestis brasileiras traficadas e exploradas por redes criminosas organizadas $e$ vinculadas ao tráfico internacional de pessoas. Porém, nos espaços desta pesquisa, a saída das travestis para a Itália $e$ as condições para a permanência nos primeiros tempos se estabelece por acionamento de redes informais de amizade, gênero $e$ parentesco. Em vários trabalhos sobre migração é possível identificar o acionamento de redes sociais que possibilita a saída $e$ a recepção nos locais de destino. Essas ações, que envolvem as informações sobre o local, o compartilhamento ou a indicação de abrigo, até mesmo o empréstimo ou a compra de passagens, são reconhecidas e nomeadas por diferentes sujeitos envolvidos na transação como "ajuda". As redes sociais acionadas pelas travestis para alcançarem seus sonhos, embora mantenham semelhanças com as acionadas por diferentes sujeitos "em trânsito", poderiam ser precipitadamente identificadas como rede de aliciamento $e$ extorsão. A versão de Rita colabora para pensarmos nessa situação:

Rita é considerada belíssima ${ }^{13}$, desembarcou na Itália pela primeira vez em 1996, foi uma das primeiras travestis de Uberlândia a pisar o solo italiano. Para isso, anteriormente permaneceu por dois anos em São Paulo até que adquirisse conhecimento.

o primeiro sonho da travesti é o peito, a Itália vem depois... comigo foi assim. Primeiro eu fui para São Paulo, aprendi a me virar na noite. São Paulo era uma escola, ninguém ia para a Europa sem passar por São Paulo antes. Eu cheguei aos 17 anos, e lá fui ficando, juntei o dinheiro da prótese,

\footnotetext{
${ }^{13}$ Termo êmico para definir as travestis que ao promoverem modificações corporais obtiveram sucesso, na avaliação do grupo, se aproximando de um modelo de beleza estabelecido para a mulher ocidental. Segundo Pelúcio (2005), estas seriam consideradas "Tops".
} 
Ser européia e o babado da prostituição

aprendi sobre os hormônios e conheci a minha mãe, ${ }^{14} \mathrm{com}$ o tempo, ela confiou em mim e disse que eu estava pronta, que ia me ajudar. Comprou as passagens e embarcou comigo para a Europa. Quando eu cheguei fui morar na casa dela, fiquei lá por quase um ano. Ela me acompanhou ate que eu aprendesse o idioma, quando eu fui não sabia uma palavra [risos]. Aprendesse as normas depois disse: segue sua vida. Eu paguei direitinho, foram 2.500 dólares, era muito dinheiro porque o dólar era valorizado, nem mesmo existia o euro, na Itália era a lira. Mas, os programas eram em dólar e eu paguei antes de 06 meses, ela dizia que não tinha pressa, mas eu sei que temos que pagar nossas dívidas, não é assim com os bancos?

A fotografia dessa mãe está no porta-retrato em cima da mesa da sala. Em algumas fotos de seus álbuns de viagens pela Grécia, França e Suíça encontro sua mãe entre as turistas. A quantidade de álbuns e pequenos souvenires trazidos como recordação são testemunhos de uma vida que em nada remete à exploração ou ao cárcere. Nas fotografias das viagens percebo que Rita está sempre acompanhada de amigas travestis brasileiras com quem vive ou compartilha espaços de sociabilidade na Itália. Maridos de amigas, familiares dos maridos e namorados vez ou outra também integram o grupo. Cartões e postais estão distribuídos pela casa, em um deles foi possível ler: "para minha mãe". As travestis reinventam seus laços de parentesco, assim, Bruna e Rita são reconhecidas como primas, embora não possuam laços de consangüinidade.

Bruna viajou para Europa em 2007, as passagens e a estadia foram presentes de aniversário enviados pela prima e suas amigas. Utilizou uma rota comum para ingresso, sem intermediações. Ela afirma não ter tido nenhuma dificuldade para ingressar em Portugal e, posteriormente, desembarcar em Bologna. Mesmo não

${ }^{14}$ Termo êmico utilizado para definir, na rede de relações, aquela a quem se deve respeito. Nesse contexto, indicaria também uma origem, um pertencimento a um determinado grupo. 
tendo embarcado com objetivo de trabalhar, poderia ser considerada suspeita por ser travesti, mas denuncia o preconceito que sofreu no retorno ao Brasil, tendo as malas revistadas e um tratamento que não considerou digno no aeroporto de Guarulhos. A experiência de Bruna é única entre as entrevistadas (indocumentadas), até mesmo Rita que se recusa a comprar passagens de companhias que farão conexões na França, justifica que, mesmo após estar regularizada na Itália, foi desrespeitada em um dos aeroportos daquele País.

A experiência de Rita soma-se à percepção de Priscila. Questionada se, para colaborar comigo na pesquisa, ela viajaria para a Itália através de um vôo direto, Guarulhos/Fiumiccino ou Guarulhos/Malpensa. Ela sorri e responde:

Jamais. A senhora entraria linda e mulher e eu? Voltaria imediatamente: travesti. Não importa quanto de dinheiro temos no bolso e nem mesmo o que vamos fazer lá.... não entramos.

O uso das chamadas rotas alternativas coloca, de fato, as travestis em situação de perigo, a despeito das histórias relatadas sobre essa aventura, percebo que o ingresso na Europa, cada vez mais, se atrela ao uso do que consideram como rotas alternativas. ${ }^{15}$ A condição vivida pelas travestis na "dupla ilegalidade" no mercado do sexo se constitui como fonte do poder e controle que exercem sobre os/as migrantes, conforme identificou Adriana Piscitelli (2008). Nesses casos, as leis que impossibilitam a migração e o trabalho sexual legais constituem os principais obstáculos para os/as migrantes que se inserem na indústria do sexo no exterior.

Laura não contraiu dívidas para ir à Itália. Reuniu recursos suficientes a partir de seu trabalho na prostituição somados aos rendimentos da pensão por morte de seu pai. No entanto, não

${ }^{15}$ Como uma das condições para as entrevistas, não farei referência a nenhuma rota informada. 
Ser européia e o babado da prostituição

viajou sozinha, porque não conhecia as rotas para ingresso no país de destino. "Não tinha conhecimento" e utilizou o mesmo esquema que Mariana para aportar em Milão, viajaram juntas através das rotas alternativas, o mais significativo é que, após seu retorno, Laura adotou o mesmo sobrenome que a dona da casa onde residiu.

É significativo o número de travestis que chegava da Itália e, mesmo residindo em apartamentos individuais, visitava com freqüência as donas das casas de pensão e mantinham com estas uma relação de afetividade, muitas permaneceram por semanas na casa antes de visitar a família. A permanência na casa era referida como um tempo de descanso e também de rever as amigas. Visitas médicas para exames de rotina ou mesmo para intervenções de cirurgias plásticas também foram observadas.

\section{O trabalho das travestis}

Ao migrar, o sonho motivador da travesti é trabalhar na Europa e, nessa perspectiva, este se alinharia ao de milhares de brasileiras que deixaram o país para trabalhar (Assis, 2007). O fato de que o trabalho a ser exercido pelas travestis é majoritariamente a prostituição coloca esse grupo em destaque na discussão da exploração sexual e do tráfico de pessoas. Meu argumento tentará demonstrar que o duplo estigma da condição de prostituta $e$ "indocumentada" colocam as travestis em situação de vulnerabilidade na Itália.

Em todas as entrevistas, é imperativa a negativa de que são enganadas ou aliciadas para exercer a prostituição forçada no exterior.

se você é travesti e batalha aqui no Brasil, você vai para a Itália fazer o que? A badante? Ninguém vai dizer que foi enganado... e se dizer é mentira [risos]. 
A fala de Bruna, relatada acima, encontra correspondência com os dados obtidos através da coordenadora de uma das Unidades que compõe o Projeto Roxanne. Em 2007, o projeto contabilizou 1497 prostitutas nas vias e estradas de Roma - na região sobre sua responsabilidade -, entre elas, $30 \%$ são trans (termo utilizado no projeto para englobar travestis e transexuais) $e$ desse percentual $97 \%$ são brasileiras. Ou seja, de acordo com essa Organização, em 2007, trabalharam nas ruas de Roma aproximadamente 435 trans brasileiras somente na região do PARSEC V. ${ }^{16}$ Nesse período, o projeto não registrou nenhuma queixa de travestis ou transexuais que se considerasse traficada ou explorada. No entanto, as integrantes da Organização justificam sua atuação inicialmente calcada na vitimização das travestis:

elas não se percebem exploradas, elas têm medo de denunciar, elas têm medo das cafetinas. É tanta violência, que elas nem mesmo sabem que são vítimas.

As percepções da coordenadora e da mediadora cultural se afinam, documentos nos quais prevalecem os argumentos respaldados no campo das ciências ditas "psi" (OIT, 2006), onde não seria suficiente a pessoa não se perceber explorada para afastar o conceito de tráfico, porque quem está autorizado a dizer se esta pessoa é explorada é um outro. ${ }^{17}$

\footnotetext{
${ }^{16}$ Os dados apresentados mostram a supremacia numérica das travestis brasileiras em Roma, um outro indício dessa presença pode ser percebido através da maneira coloquial com que muitos italianos, ao se referirem às travestis, empregam, como termo depreciativo viado brasiliano. É significativo ressaltar que não é comum o uso entre os italianos de palavrões e xingamentos referentes à homossexualidade.

${ }^{17} \mathrm{O}$ documento faz referência específica à síndrome pós-traumática que, na atual versão da Classificação Internacional de Doença (CID-10), estaria contemplado com o diagnóstico de F43.0 - Reação aguda ao stress. A atuação dos poderes jurídicos, outorgando aos detentores dos saberes "psi" o direito de dizer sobre o outro, é tema relevante de reflexões e debates no campo da sexualidade, ver Bento (2006).
} 
Ser européia e o babado da prostituição

No entanto, Letícia relata um episódio diferente. Aos 26 anos seria facilmente reconhecida como a típica "européia e top" entre as travestis. Ela rejeita os rótulos e, sentada na beira da piscina, se dispõe a falar um pouco de sua experiência na Europa. A Itália não se apresentava como um sonho até que uma amiga travesti, numa das visitas à sua cidade, fez o convite. Em 2000, ela desembarcava em Milão com a perspectiva de fazer a vida, trabalhou nas ruas por um ano até alugar seu próprio apartamento, a partir de então trabalha somente em casa, por telefone e internet. Os retornos ao Brasil são freqüentes, ora para visitar a família que reside no sul do Brasil, visitar as amigas (inclusive em Uberlândia), ora para visitar, em Salvador, a família do então namorado brasileiro que conheceu em Milão e com quem residiu por dois anos. Ela fala de seu acordo para a primeira viagem:

O combinado não é caro. Paguei sim, 8.000 Euros pelas passagens e empréstimos para iniciar a vida. Em menos de dois meses já havia pagado a minha dívida, então ela [a amiga travesti] me procurou e disse que precisaria de mais dinheiro. Não achei justo. Procurei a questura e então foi minha decepção, o policial falou: "Você quer fazer uma queixa contra uma cidadã italiana? Ela é documentada $e$ você? Você não é nada, é menos do que um cachorro, porque aqui até os cachorros possuem documentos". Então negociei com ela, paguei $50 \%$ do valor que ela me pediu $e$ nunca mais nos falamos.

Como identificou Adriana Piscitelli (2006) em relação às mulheres, um certo percentual de juros cobrados pela passagem é considerado lógico e justo, entre as travestis com as quais trabalhei, o sentimento de ser explorada surge apenas quando são acrescidas exigências ao contrato inicial. Esse sentimento, no entanto, não estabelece correspondência com o que está estabelecido como tráfico. As travestis que entrevistei não se consideram vítimas de tráfico ou exploração. Laura pagava 350 
Flávia Teixeira

Euros por semana para residir em um apartamento com outras três travestis. Perguntei se considerava o valor abusivo:

você tem que pagar para comer em qualquer lugar, em qualquer casa onde more, você pensa que vai comer de graça? Tem que pagar para morar, pagar as contas, é o certo. 350 Euros é uma noite de trabalho, ou até menos, então não é muito. Compensa.

Embora as travestis brasileiras se constituíssem como os sujeitos da investigação, a existência das travestis peruanas principalmente em lugares de poder - não poderia passar despercebida conforme o depoimento de Priscila sobre a prática do pedágio:

eu cheguei na rua, sabia em que região minha amiga trabalhava, $e$ então esperei... estava quase amanhecendo quando ela chegou, fomos para a casa dela e três dias depois eu fui morar numa casa com outras quatro travestis. Não paguei para trabalhar na rua, mas tem alguns pontos que as mais antigas, as peruvianas ${ }^{18}$ controlam e então... quando quero trabalhar lá eu pago, pago porque compensa.

A fala da Priscila exemplifica que, nesse contexto, os lugares não são fixos. Sendo a dona da pensão em Uberlândia poderia ser "facilmente" encaixada nos parâmetros do Código Penal brasileiro, mas na situação acima relatada preencheria critérios para ser considerada como vítima.

Rita coloca uma outra questão sobre o controle dos pontos nas ruas:

${ }^{18}$ Todas as travestis que entrevistei tiveram contato com as travestis do Peru, chamadas em italiano de "peruvianas", termo incorporado ao léxico das travestis de Uberlândia, principalmente para dizer sobre travestis mais velhas (não tenho dados que informem sobre sua recorrência em outros locais). 
Ser européia e o babado da prostituição

eu penso que é igual ao serviço de táxi, cada um tem seu ponto. O táxi registrado no aeroporto de Uberlândia pode estacionar e pegar passageiros no centro? Não. Então tudo tem que ter regra, ter ordem, também a prostituição.

$\mathrm{Na}$ percepção das entrevistadas, o rufianismo não constitui uma regra da prostituição para as travestis. Todas exemplificaram o que consideravam exploração, relatando a situação das mulheres romenas, africanas e albanesas:

essas organizações e a polícia italiana deveriam cuidar das mulheres romenas, africanas, albanesas estas sim, são exploradas pelos cafetões. Eles ficam esperando elas voltarem do programa, por vinte e trinta minutos, porque dá para calcular o tempo que gasta, e quando elas chegam eles levam todo o dinheiro. As mulheres ganham mais dinheiro, se uma travesti recebe 400 Euros numa noite, as mulheres recém 700 Euros, principalmente as albanesas e romenas porque são lindas, brancas.

As travestis entrevistadas se reconhecem como exploradas na Itália, em diferentes contextos, no entanto, percebo a dificuldade das entrevistadas das ONGs de compreenderem os sentidos atribuídos por elas a seus cotidianos. Letícia e Clarissa trabalham nos seus próprios apartamentos, atendem seus clientes que as encontram através dos sites na internet ou telefone celular, sendo que a segurança e a comodidade compensariam a despesa de manter o aluguel, entendido como exorbitante: "Não tem que trabalhar na rua ...todos os dias na rua... o frio na rua... os mosquitos nas regiões de bosque, tem que correr da polícia...”.

Alugar um apartamento é um desafio e uma negociação que envolve acionar uma rede de amigos cidadãos ou documentados para mediar a transação. A exploração das travestis não se resumiria ao universo da prostituição $e$ nem mesmo estaria marcada apenas pelo fato de exercerem a prostituição. Ser trabalhador indocumentado coloca qualquer migrante em situação 
de fragilidade em terras estrangeiras, como identificado em outros trabalhos sobre a condição do migrante:

vou te dar um exemplo, se o apartamento para um italiano é alugado por 350, 450 Euros, para um estrangeiro sem documentos eles alugam por $1.300,1.500$. Pedem três aluguéis de calção, o dinheiro da taxa da agência e mais o aluguel adiantado. E por qualquer coisa você pode perder o apartamento. E quando perde... perde tudo. Da última vez, a panela caiu no chão, a vizinha reclamou, a polícia veio $e$ fechou o apartamento.

Essa impotência diante dos cidadãos do lugar coloca as travestis em outras situações nas quais se percebem exploradas, ser travesti e estrangeira implicaria em ocupar um lugar de menor condição para negociar, conforme relata uma das entrevistadas:

Você chega a uma loja e quando vai pagar no caixa, o preço para você é maior, mesmo você vendo o preço na etiqueta.(...) Eu pago, vou reclamar para quem?

Nem todas as travestis que estiveram por uma ou mais temporadas na Itália desejam repetir a experiência. Mariana viajou com recursos próprios, mas dividiu a casa com outras travestis de Uberlândia por quatro meses e diz que não voltaria. A justificativa para essa "desilusão" é a rua. As difíceis condições de trabalho nas ruas e a sua dificuldade em se adaptar aos clientes italianos. Embora ela não tenha mencionado um possível fracasso na experiência, não observei nenhuma aquisição de bens materiais após seu retorno.

Talvez isso contribua para explicar a desilusão, pois como aponta Larissa Pelúcio (2005), o sucesso desse empreendimento é mensurado pelo grupo quando, no retorno ao Brasil, elas adquirem carros, casas, terrenos. Mas o maior destaque é dado ao corpo. Os cuidados corporais expressos nos cabelos, próteses, lipoaspiração, depilação a laser, e roupas, perfumes, jóias e 
Ser européia e o babado da prostituição

acessórios: as grifes italianas circulam no grupo como testemunhas deste sucesso.

Durante a Parada do Orgulho Gay, percebi que são os laços afetivos que mantém Mariana no Brasil; considerada belíssima, seu suposto fracasso na Itália poderia ser atribuído, em parte, ao namoro com uma travesti que permaneceu aqui. Parece-me que, também para as travestis, a decisão sobre migrar e permanecer na Itália pode ser uma estratégia individual de ascensão social, mas é marcada por outras escolhas e projetos, por exemplo, afetivos.

Quando questionei sobre como vivem as travestis em Roma, a mediadora me contou acerca de uma visita que realizou a um local pobre, onde várias travestis residiam numa mesma casa em condições precárias. Também o fato delas raramente serem vistas circulando durante o dia pela cidade parece alimentar a idéia de que elas residem em situação de cárcere. Desconfio que o desconhecimento das realidades vividas pelas travestis no Brasil colabora para distanciá-las das ONGs, reafirmando discursos com os quais as travestis não se identificam. Como já foi dito anteriormente, na Itália, muitas travestis vivem em situação análoga à do Brasil, sem que seja compreendido como cárcere ou exploração sexual, observa-se a mesma forma de moradia coletiva, comum no Brasil, em que uma travesti é a proprietária ou locatária do imóvel $e$ as outras residem num sistema de pensionato, pagando diárias referentes ao custo da moradia. Em algumas casas, a alimentação está incluída no preço da diária, em outras não. Não percebo uma regra específica para esse contrato. No Brasil, o preço é estabelecido diariamente e na Itália semanalmente. No entanto, isso não reduz a percepção do fenômeno da exclusão social denunciado por Wiliam Peres (2005) e Maitê Scheneider (apud Peres, 2005), no qual as diferentes expressões da violência desencorajam as travestis a estarem no espaço público durante o dia.

$\mathrm{Na}$ Europa, esse cerceamento pode estar mais associado ao fato de estarem como migrantes indocumentadas, conforme os relatos de Priscila e Letícia. Agosto é um período de férias em 
Milão, um período considerado difícil por algumas travestis. A dificuldade não está na escassez de clientes, ou relacionada às intempéries do clima. A diminuição do número de pessoas circulando durante o dia deixa maior espaço de visibilidade para as travestis serem "vistas" pela polícia.

Eles acham a gente de longe. Podemos estar andando na rua, mas somos levadas para a questura, uma vez eles me colocaram na viatura... circularam pela cidade por umas três horas, depois me soltaram porque houve um problema em que um indiano matou um italiano, eles me deixaram na rua e saíram loucos.

Nesse contexto, também são pertinentes as considerações de Adriana Piscitelli (2006) sobre a condição das prostitutas brasileiras indocumentadas na Espanha e as práticas repressivas deste governo em relação à deportação, consideradas por elas como o maior perigo a ser enfrentado. A folha de via obrigatória é um documento conhecido das travestis, elas sabem como funcionam os mecanismos da deportação e algumas também experimentaram a prisão na Itália. Elas sabem que as informações que circulam nas redes são preciosas. Semelhante às considerações de outros estudos sobre trabalhadores indocumentados, quanto maior e mais bem articuladas as redes, maiores são as chances no local de destino (Assis, 2007:752).

A socialização do conhecimento integra a rede de ajuda $e$ permite, inclusive, a circulação do dinheiro entre as travestis e seus familiares, pois algumas preferem depositar o dinheiro na conta de uma travesti amiga. Adriana Piscitelli (2007c) enfatiza a importância de se reconhecer o espaço transnacional criado também a partir da circulação de dinheiro do mercado do sexo também nos países de origem das prostitutas. $\mathrm{O}$ dinheiro ganho pelas travestis no exterior circula no Brasil e é recorrente o relato de que o primeiro dinheiro ganho na Europa é destinado à compra de uma casa para mãe no Brasil. 
Ser européia e o babado da prostituição

Não comprei uma casa para minha mãe, porque travesti quando ganha dinheiro, pensa logo na mãe, mas ela já tinha. Então, reformei tudo. Pus do bom e do melhor na casa. Agora, mando o salarinho dela todo mês, é sagrado (Rita).

A primeira coisa? Comprei um terreno. A casa da minha mãe eu já tinha comprado com o dinheiro aqui do Brasil mesmo (Priscila).

Eu enviei 127 mil reais para ela [a mãe] comprar uma casa. Também estudei meus irmãos, paguei estudo dos dois. E depois levei minha irmã para morar comigo, depois meu irmão (Letícia).

Comprei uma casa para minha mãe, e ajudo em casa todo mês. Dou o que precisa, cuido dos sobrinhos (Clarissa).

O dinheiro ganho na Europa empodera as travestis diante da família. Mas não apenas diante dela, Priscila conta, entre gargalhadas, notícias de uma travesti (que conheci antes de ir para a Europa) que construiu uma casa numa cidade do interior de Goiás ao lado da casa do prefeito da cidade. "Uma casa que é um palácio [risos] tombou a casa do prefeito".

Não estou vinculando aqui a migração das travestis à situação de pobreza, mas sim às expectativas de uma vida melhor, comungando das observações de Adriana Piscitelli (2008) em relação às prostitutas brasileiras na Espanha. Os critérios utilizados por elas para classificar o que seria uma vida melhor podem variar, demonstrando a diversidade que compõem esse universo. Utilizo um fragmento do caderno de campo para exemplificar a variação:

quando estou muito triste, desanimada, abro meus armários e fico lá da cama namorando meus vestidos $e$ penso: vale a pena. Antes eu não tinha somente um, um verde limão que trazia na bolsa. Agora tenho Dolce \& Gabbana, Versace. São muitos [os vestidos], né? (Priscila). 
Flávia Teixeira

\section{Prostituição: produções discursivas}

Durante a pesquisa de campo realizada em maio de 2008, houve um acirramento dos discursos e práticas contra migrantes indocumentados em Roma. O governo acenava com discursos e a polícia colocava em prática. Assim como no Brasil, na Itália, a prática da prostituição em si não se configura como crime, embora a intervenção da polícia italiana parece guardar semelhanças ao que ocorre em terras brasileiras, no entanto, utiliza-se de estratégias diferentes para penalizar os clientes da prostituição. Segundo Marlene Rodrigues (2004), no Brasil, a criminalização das diversas atividades que cercam o cotidiano da prostituição, bem como a dificuldade encontrada pelo sistema judiciário para diferenciá-la do lenocínio, e a recorrente compreensão da prostituição como uma questão de (des)ordem pública, favorecem o entendimento de que o exercício desta se inclui entre as competências da polícia. Não sendo irrelevantes as denúncias de que essas ações, não raramente, são desenvolvidas em situações que ferem os direitos das prostitutas e são marcadas por violência.

Em Roma, o episódio da prisão de uma travesti brasileira foi veiculado pelo telejornal $e$, logo após, disponibilizado no youtube. ${ }^{19} \mathrm{~A}$ ação chamou a atenção não somente pelo aparato policial envolvido na ação, mas pela violência com que a travesti foi arremessada para dentro da viatura policial, e principalmente pelos aplausos aos policiais $e$ insultos dirigidos a ela pela população que assistia a intervenção policial.

\footnotetext{
${ }^{19}$ Informação veiculada no Jornal da Emissora Rai Tre, 17 de maio de 2008. Reportagem disponível em http://br.youtube.com/watch?v=wj_X2Tn6fyg
} 


\section{Trans: è tutto su YouTube}

In due giorni 11 mila visualizzazioni della protesta al Prenestino

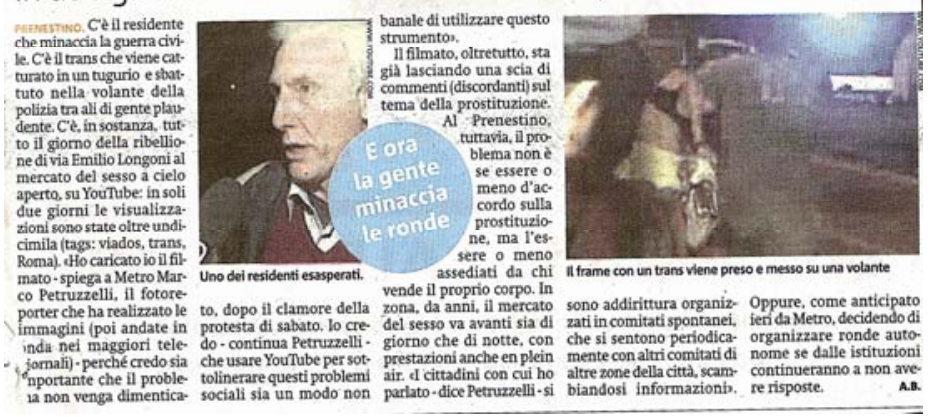

Fonte: www.metronews.it publicado em 20 de maio de 2008.

O apoio popular observado nessa ação soma-se aos apelos veiculados nas reportagens em jornais e revistas no mês de maio, demandando da polícia ações para o restabelecimento da ordem pública. O discurso oficial não é apenas o combate a exploração sexual, mas também ao tráfico de seres humanos para fins de exploração sexual. Por esse motivo, as ações das ONGs subvencionadas pelo Estado estão voltadas para a identificação e proteção dessas vítimas. No entanto, a ação da polícia, observada no episódio relatado, desrespeita os princípios da Convenção de Palermo. $^{20}$

Mesmo quando o discurso oficial e a mídia insistem na associação entre prostituição e tráfico de seres humanos para fins de exploração sexual, percebo a ausência de políticas públicas para a proteção das vítimas. Por exemplo, embora o projeto Roxanne seja reconhecido como uma estratégia para que as

${ }^{20}$ Princípio da não-discriminação: os países não devem discriminar as pessoas traficadas no Direito Material ou Processual, nas políticas públicas ou em suas práticas. Segurança e tratamento justo: ao invés de considerá-las como migrantes indocumentados, os países devem reconhecer que as pessoas traficadas são vítimas de graves abusos de direitos humanos, assim como tutelar seus direitos e protegê-las contra represálias e perigos. 
travestis denunciem os traficantes, somente no início de 2008 o governo passou a oferecer, em Roma, uma casa-abrigo que recebesse as travestis, segundo uma das entrevistadas. Quando questionada sobre o número de travestis que recebeu a permissão de trabalho após a denúncia, ela diz não ter notícia de qualquer evento semelhante envolvendo as travestis. Relata que as duas únicas travestis que teve notícia, mesmo mediante a denúncia, retornaram para o Brasil. Justifica tal fato pela morosidade do processo e não saberia dizer se foram expulsas.

A Itália parece seguir a perspectiva apontada por Adriana Piscitelli (2006) em que as medidas para erradicar o mercado do sexo são consideradas como medidas anti-tráfico e vice-versa. Para exemplificar, utilizo o fragmento de uma reportagem veiculada em 2007 sobre o lançamento oficial de um conjunto de medidas para "limitar" o fenômeno da prostituição na via Salaria, em Roma, através da emissão de multas aos clientes associadas a um processo educativo:

Conjuntamente com o verbal, aos clientes das prostituas será distribuída uma pequena cartilha informativa elaborada pela assessoria de Comunicação e Igualdade de Oportunidade em colaboração com a assessoria de Políticas Sociais e da Presidência do IV Município. Uma cartilha que objetiva sensibilizar os clientes das prostitutas sobre as conseqüências de seus comportamentos: os informa sobre as condições de escravidão que são submetidas a maior parte das prostitutas, sobre o fato de que o tráfico da prostituição é o terceiro trafico mundial das organizações criminosas depois do de drogas e armas, e sobre o fato de que estar com uma prostituta menor constitui crime penal (tradução livre). ${ }^{21}$

21 "Contestualmente al verbale, ai clienti delle prostitute verrà consegnata una piccola brochure informativa predisposta dall'assessorato capitolino alla Comunicazione e Pari opportunità, con la collaborazione dell'assessorato alle Politiche sociali e della Presidenza del IV Municipio. Una brochure che si prefigge di sensibilizzare i clienti delle prostitute sulle conseguenze del loro 
Ser européia e o babado da prostituição

Em relação ao trato da questão da prostituição, o modelo abolicionista seria o estatuto legal mais difundido entre os países da União Européia e, segundo Adriana Piscitelli (2007b), esse modelo orientou a Convenção para a Supressão do Tráfico de pessoas e exploração da prostituição, de 1949. A vinculação da prostituição com o tráfico e a exploração é explícita no documento destinado aos clientes e a saída vislumbrada para proteção das mulheres seria, nessa perspectiva, abolir a prostituição.

A proibição de circulação e parada não se restringiu à via Salaria e, ante minha determinação em circular nos espaços da prática de prostituição da região adstrita de minhas entrevistadas, fui advertida de que a polícia não permitiria minha entrada na área, além da possibilidade de ter o carro multado. Fui convidada a realizar o percurso no automóvel da integrante do projeto em horário oficial e posteriormente comunicar o departamento da Comuna de Roma com agendamento de dia e horário específicos. A restrição de transitar em local público não me passaria despercebida. A tranqüilidade com que me informavam sobre essas restrições me incomodava, uma ação que na minha percepção parecia tão arbitrária era interpretada como uma simples questão administrativa, nomeada com "Divieto di Fermata contro la prostituzione".

Escolhi o horário da tarde para conhecer sozinha esses espaços, porque me parecia mais seguro. Ao me aproximar da Piazza Pino Pascale (cenário do episódio da prisão de uma travesti, relatado abaixo), o sinal de "divieto di transito" anunciava a estratégia adotada para coibir a prostituição nos espaços públicos: a punição aos clientes, não mais em função da compra do serviço em si, mas da circulação (neste caso, os horários

comportamento: li informa sullo stato di riduzione in schiavitù cui sono sottoposte la maggior parte delle prostitute, sul fatto che la tratta della prostituzione è il terzo traffico mondiale delle organizzazioni malavitose dopo quello della droga e quello delle armi, e sul fatto che andare con una prostituta minorenne costituisce un reato penale". Disponível em http://www.romanotizie.it/spip.php?article3335 (consultado em 22/05/2008). 
estavam determinados na placa) e/ou parada em local não permitido.

As placas de sinalização de proibição de parada $e$ estacionamento estão distribuídas ao longo da Avenida. Para mim, que não sou especialista em trânsito, não ficava evidente que a avenida em questão respondia aos critérios estabelecidos no Artigo 158 do Código de Estrada italiano ${ }^{22}$ para instituir o "divieto di transito" e o "divieto di fermata". Uma avenida larga, que, na esquerda, possui um grande local destinado a estacionamento separado por um muro grafitado que parece demarcar os limites de uma fábrica aparentemente desativada. No lado oposto, um largo espaço (que parecia também um estacionamento) utilizado para aulas de instruções sobre o trânsito. A presença da viatura policial também anuncia que a fiscalização do espaço se destina a regulamentar os usos legítimos deste especo e quem são as pessoas que podem usufruir o espaço público.

Durante o período que permaneci observando, três carros foram abordados pela polícia, os três eram conduzidos por homens desacompanhados e, após serem identificados, eram liberados. No lado oposto, três travestis permaneciam sentadas ao lado de um banheiro público. No mesmo período, dois possíveis clientes se aproximaram das travestis, um conduzindo uma motocicleta e o outro um automóvel. Cada um deixou o local acompanhado por uma travesti. Outra travesti chegou caminhando sozinha, após ter descido de um carro alguns metros acima. Toda essa movimentação parecia desenrolar alheia às placas de trânsito e/ou a presença da polícia.

No entanto, bastou a minha aproximação para perceber a desconfiança que um estranho suscitava - as travestis abandonaram o local, evitando o contato. A facilidade com que deixaram o local mostrou que, embora sentadas e aparentemente

${ }^{22}$ Nuovo codice della strada, decreto legisl. 30 aprile 1992 n. 285, disponível em: http://www.ricercagiuridica.com/Codici/vis.php?num =3358 (consultado em 25/05/2008). 
Ser européia e o babado da prostituição

tranqüilas, o local permite que elas rapidamente fujam dali sem serem abordadas.

Foram muitas as tentativas frustradas de entrevistar as travestis nas ruas e estradas de Roma. Quando não fugiam, elas negavam serem brasileiras, diziam serem italianas ou mesmo peruvianas. Essas recusas e desconfianças das travestis não se reduzem ao fato de eu ser uma pesquisadora brasileira desconhecida. Esse comportamento foi relatado como recorrente também em relação às pessoas que trabalham na Unidade de Estrada. No entanto, em parte, as atitudes de desconfiança podem ser justificadas porque a inserção na rede de relações das travestis depende de uma credencial que naquele contexto eu não possuía. E em parte, pode ser compreendida através de um fragmento da entrevista com a mediadora cultural da Unidade de Estrada, que ao comparar o projeto que coordeno no Brasil com o desenvolvido por elas na Itália explicou: "nós estamos de lados diferentes, eu represento o governo e você defende as travestis". Penso que nesse momento, ao utilizar os pronomes eu e você, estaria construindo uma metáfora para dizer das posturas opostas dos governos brasileiro $e$ italiano ao lidarem com a questão das travestis e também da prostituição. ${ }^{23}$

Enquanto preparava este texto, foi publicada uma reportagem no jornal da internet com o título: "Le prostitute sono soggetti pericolosi": a Rimini "guerra' alla lucciole". ${ }^{24}$ A reportagem

${ }^{23}$ No Brasil, o movimento nacional das travestis está organizado e mantém interlocução significativa com a proposição de políticas públicas, por exemplo, o Encontro Nacional de Travestis e Transexuais na Luta contra a Aids (ENTLAIDS), financiado pelo Programa Nacional de Aids do Ministério da Saúde, que realizou sua décima quinta edição em setembro de $2008 \mathrm{em}$ Salvador; mais recentemente, a I Consulta Nacional sobre DST/Aids, Direitos Humanos e Prostituição foi organizada pelo Programa Nacional de DST e Aids e realizada em Brasília, reunindo lideranças da Rede Brasileira de Prostitutas, da Articulação Nacional de Travestis e Transexuais, do Coletivo de Transexuais e representantes do Governo.

${ }^{24}$ Disponível em http://www.romagnaoggi.it/rimini/2008/8/4/99103/ (consultada em 04/08/2008). A palavra "guerra" também foi escolhida compor o título da 
informa que na cidade de Rimini, as prostitutas estrangeiras foram consideradas pelo questore, Antonio Pezzano, como sujeitos perigosos. E foi empreendida uma verdadeira caça a elas durante o mês de julho revelada pelos números apresentados: 47 assinaram a folha de via obrigatória e outras 40 foram denunciadas e aguardam o desenrolar do processo para serem ou não repatriadas.

A ação foi deflagrada a partir de uma emenda apresentada ao Senado, ainda não aprovada, para modificar a Lei 1423 de 1956, que trata das questões das punições às pessoas consideradas perigosas que colocam em risco a integridade física ou moral dos menores, a saúde, a segurança ou a saúde pública, incluindo as prostitutas. Ao estabelecer como perigosas todas aquelas que vivem da própria prostituição $e, \quad$ portanto, estariam sujeitas às penalidades previstas na lei, em princípio, poderia marcar, na Itália, a passagem do modelo abolicionista para o modelo proibicionista com a penalização as prostitutas. É exatamente a pena a ser aplicada que explicita a questão não é tão transparente assim, o delito está relacionado às migrantes, pois não parece lógico penalizar as prostitutas italianas com a assinatura da folha de via $e$ o repatriamento.

reportagem "Guerra alle prostitute di strada in arrivo foglio di via e espulsione". Disponível em http://www.dirittiglobali.it/articolo.php?id_news=6736 (consultada em 05/08/2008). 
Ser européia e o babado da prostituição

A proposta levada ao Senado italiano, que considera as prostitutas como perigosas, poderia até mesmo ser interpretada como um marco explícito do combate à prostituição. No entanto, a relação entre travestis e periculosidade antecede este projeto, como mostram as fotos de um dos locais de "prostituzione di strada" visitados. Percorri algumas vias de acesso ao mar de Ostia, partindo de Roma e cruzando o Parque de Castel Fusano, onde várias placas de sinalização indicativas do perigo de "animali selvatici vaganti" estavam distribuídas ao longo da estrada (fig. 1).

As placas dividiam o espaço com cadeiras velhas, preservativos usados, restos de alimentos, indícios do uso constante daqueles espaços. As clareiras em direção ao interior do parque são indicativas da circulação de prostitutas e clientes, o local não dispõe de iluminação (fig. 2). Ao examinar as fotografias, Priscila explica que a iluminação, durante a noite, é obtida a partir de pequenas latas com combustível Gasolio. "Os clientes já sabem, perto de cada latinha tem uma prostituta". ${ }^{25}$ Observando os espaços e as situações de trabalho das travestis, ressalto que em nenhum momento foram flagradas falas, dos representantes das ONGs, do Estado, ou mesmo da população, problematizando essas precárias condições para o exercício da prostituição, ou seja, nenhuma preocupação foi demonstrada no sentido de considerar essa situação em particular como uma forma de trabalho degradante. Uma revista de distribuição local anunciava a proximidade da estação do verão e enfatizava a preocupação da população com problemas como tráfego, estacionamento $e$, principalmente, a presença (visibilidade) das prostitutas nas vias de acesso ao mar ${ }^{26}$; novamente a prostituição surge restrita como um problema de (des)ordem pública.

${ }^{25}$ Algumas cenas do filme Tirésia ilustram essa vivência da prostituição de estrada na França. Tiresia, direção de Bertrand Bonello, França/Canadá, 2003.

${ }^{26}$ L'OCCHIO che..., ano 4, no 7, maggio 2008 (também disponível em www.occhioche.it). 
Flávia Teixeira

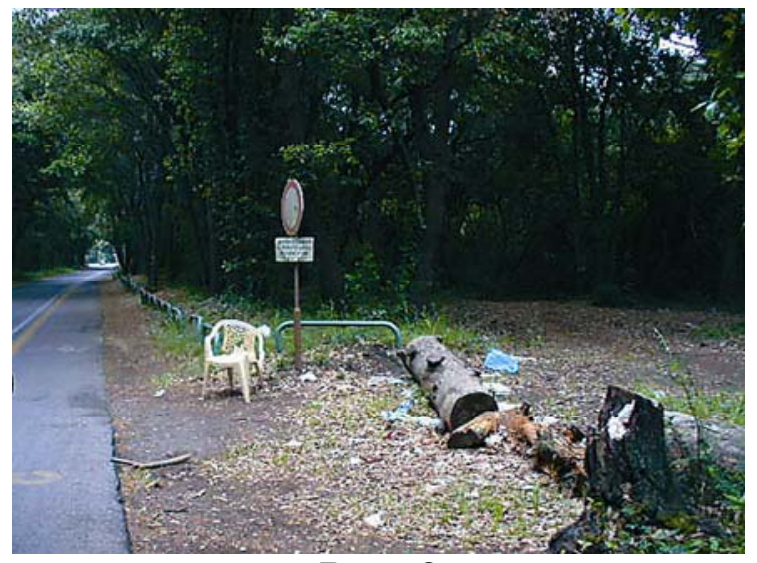

Figura 2

\section{Enquanto a Emenda tramita no Senado...}

Este artigo pretendeu oferecer uma leitura, parcial, da circulação das travestis no mercado do sexo na Itália e demonstrar que a constituição de suas redes, marcadas pelo gênero e laços de amizade, guarda semelhanças com as redes acionadas por outros migrantes em busca de uma outra vida em outro lugar. O exercício da prostituição também as aproxima, não somente no plano teórico, das brasileiras prostitutas. Mas evidencio que todas as semelhanças não ofuscam as heterogeneidades. Escrevo num momento em que o cerceamento das fronteiras na Itália se intensifica, deixando as travestis em situação de dupla ilegalidade $e$ aumentando, exponencialmente, sua vulnerabilidade. Encerrando, atualizo um convite realizado por Adriana Piscitelli (2007a) ao afirmar que uma das características do movimento feminista tem sido dar voz às mulheres, particularmente às marginalizadas. O debate sobre a prostituição como trabalho oferece uma excelente oportunidade para continuar essa linha de atuação, prestando séria atenção ao posicionamento das prostitutas, individualmente e organizadas no plano regional $e$ nacional, para ampliar esse debate, considerar ainda que neste 
Ser européia e o babado da prostituição

mesmo cenário de prostituição encontram-se as travestis $e$ as transexuais.

\section{Referências bibliográficas}

Assis, G. O. Mulheres migrantes no passado e no presente: gênero, redes sociais e migração internacional. Estudos Feministas, 15(3), Florianópolis, 2007.

BenedetTI, M. Toda Feita: o corpo e o gênero das travestis. Rio de Janeiro, Garamond, 2005.

BENTO, Berenice. A Reinvenção do Corpo: sexualidade e gênero na experiência transexual. Rio de Janeiro, Garamond, 2006.

DAVIDA. Prostitutas, "traficadas" e pânicos morais: uma análise da produção de fatos em pesquisas sobre o "tráfico de seres humanos". Cadernos Pagu (25), Campinas-SP, Núcleo de Estudos de GêneroPagu/Unicamp, 2005, pp.153-184.

FerRAZ, E. A. (coord.) Travestis Profissionais do Sexo: Parcerias do Asfalto - conhecimentos, atitudes e práticas sobre o HIV/Aids em Uberlândia. Rio de Janeiro, BEMFAM, 2006.

JAYME, Juliana Gonzaga. Travestis, transformistas, drag-queens, transexuais: personagens e máscaras no_cotidiano de Belo Horizonte e Lisboa. Tese de Doutorado, Programa de Pós-Graduação em Ciências Sociais, Universidade Estadual de Campinas, 1999.

KEMPADOO, Kamala. Mudando o debate sobre o tráfico de mulheres. Cadernos Pagu (25), Campinas-SP, Núcleo de Estudos de GêneroPagu/Unicamp, 2005, pp.55-78.

KULICK, Don. Travesti: sex, gender and culture among Brazilian transgendered prostitutes. Chicago, The University of Chicago Press, 1998.

Travesti. Protituição, sexo, gênero e cultura no Brasil. Rio de Janeiro, Editora Fiocruz, 2008 [Trad.: César Gordon].

OliveIRA, Neuza Maria de. Damas de paus: o jogo aberto dos travestis no espelho da mulher. Salvador, Centro Editorial e Didático da UFBA, 1994. 
PELÚCIO, Larissa. Na noite nem todos os gatos são pardos: Notas sobre a prostituição travesti. Cadernos Pagu (25), Campinas-SP, Núcleo de Estudos de Gênero-Pagu/Unicamp, 2005, pp.217-248.

Nos Nervos, Na Carne, Na Pele. Uma etnografia sobre prostituição travesti e o modelo preventivo de Aids. Tese de Doutorado, Programa de Pós-Graduação em Ciências Sociais, Universidade Federal de São Carlos, 2007.

PERES, Wiliam. Subjetividade das travestis brasileiras: da vulnerabilidade da estigmatização à construção da cidadania. Dissertação de Mestrado, Instituto de Medicina Social, Universidade Estadual do Rio de Janeiro, 2005.

PISCITELLI, Adriana. Entre as "máfias" e a "ajuda", visões de migrantes brasileiras. 26 Reunião Brasileira de Antropologia - ABA, Simpósio Especial: Gênero no marco do tráfico de pessoas e migrantes, Porto Seguro-Bahia, 2008.

Prostituição e Trabalho. In: LIMA, Maria Ednalva Bezera de; CostA, Ana Alice Alcantara; CosTA, Albertina; ÁvILA, Maria Betania; SOARES, Vera Lúcia. (orgs.) Transformando as relações trabalho e cidadania, produção, reprodução e sexualidade. Salvador, UFBA/FFCH/CUT, vol. 1, 2007a, pp.183-195.

. Corporalidade em Confronto: Brasileiras na indústria do sexo na Espanha. Revista Brasileira de Ciências Sociais, vol. 22, $\mathrm{n}^{\circ}$ 64, 2007b.

Sexo tropical em um país europeu: migração de brasileiras para a Itália no marco do "turismo sexual" internacional. Estudos Feministas, 15(3), Florianópolis, 2007c.

Entre a Praia de Iracema e a União Européia: turismo sexual internacional e migração feminina. In: PISCITELLI, A. et alii. Sexualidades e Saberes, Convenções e Fronteiras. Rio de Janeiro, Garamond, 2004.

RODRIGUES, Marlene Teixeira. O Sistema de Justiça Criminal e a Prostituição no Brasil Contemporâneo: administração de conflitos, discriminação e exclusão. Sociedade e Estado, vol. 19, n ${ }^{\circ}$, Brasília, 2004, pp.121-150.

SILVA, H. R. S. Travesti: a invenção do feminino. Rio de Janeiro, Relume-Dumará/Iser, 1993. 
Ser européia e o babado da prostituição

Travesti: entre o espelho e a rua. Rio de Janeiro:, Rocco, 2007.

SIQUEIRA, M. S. Sou Senhora: um estudo antropológico sobre travestis na velhice. Dissertação de Mestrado, Programa de Antropologia, Universidade Federal de Santa Cantarina, 2004.

WolfF, Cristina S.; PEDRO, Joana Maria. Gênero e migrações na história entre Brasil e Itália: uma entrevista com Chiara Vangelista. Estudos Feministas, 15(3), Florianópolis, 2007.

\section{Documentos consultados}

CECRIA. Tráfico de Mulheres, crianças e adolescentes para fins de exploração sexual no Brasil. Relatório Final de Projeto de Pesquisa (PESTRAF), Brasilia, 2002. http://www.cecria.org.br/pub/livro pestraf_portugues.pdf.

SECRETARIA INTERNACIONAL DO TRABALHO. Tráfico de pessoas para fins de exploração sexual. Brasília, OIT, 2006.

SECRETARIA NACIONAL DE JUSTIÇA. Indícios de tráfico de pessoas no universo de deportadas e não admitidas que regressam ao Brasil via aeroporto de Guarulhos. Pesquisas em tráfico de pessoas, parte 2, Brasilia, 2006 (coord. técnica: Adriana Piscitelli).

ORGANIZAÇÃo INTERNACIONAL DO TRABALHO. Trabalho digno-trabalho em segurança-VIH/sida. Relatório do BIT para o dia mundial da segurança e saúde no trabalho, 2006. http://www.ishst.pt/ downloads/content/Brochura_OIT_2006.pdf

SECRETARIA NACIONAL DE JUSTIÇA/ ORgANIZAÇÃo INTERNACIONAL DO TRABALHO. Tráfico Internacional de Pessoas e Tráfico de Migrantes entre Deportados(as) e não Admitidos(as) que Regressam ao Brasil via o Aeroporto Internacional de São Paulo, Brasília, 2007. 